\title{
Warpage Reduction for Integrated Circuit in an Electronics Manufacturing Plant
}

\author{
S. Pisutkulakij \& P. Chutima \\ Faculty of Engineering/Industrial Engineering \\ Chulalongkorn University, Wangmai, Patumwan, Bangkok 10330, Thailand
}

ABSTRACT: The purpose of this research is to reduce the defect parts per million (DPPM) of the thickness out of specification caused by module warpage. Six Sigma approach was applied and the $2^{\mathrm{k}}$ full factorial design with three replicates at $95 \%$ confident level was used to determine the significant factors to the module warpage. The significant factors comprised dam temperature, fill temperature and curing temperature. BoxBehnken design was also used to optimize the level of the significant factors. The results suggest that the encapsulation machine dam temperature, fill temperature and the curing temperature should be set at $30^{\circ} \mathrm{C}$, $65^{\circ} \mathrm{C}$ and $41{ }^{\circ} \mathrm{C}$, respectively. The confirmed runs show that DPPM of the thickness out of specification is reduced from 600 to 184 .

KEYWORD: Integrated circuit; Warpage; Six Sigma

\section{INTRODUCTION}

The case study of this research was conducted in the integrated circuit manufacturing operations of a well-known semiconductor assembly company. The product of interest is integrated circuit which is widely used in the personal electronics card business. Historical data indicated that the highest defect in the process is the thickness out of specification (600 DPPM) as shown in Figure 1. Module warpage is identified to be the main cause of the problem which had a direct impact on the customers who want to use the product with inline card readers.

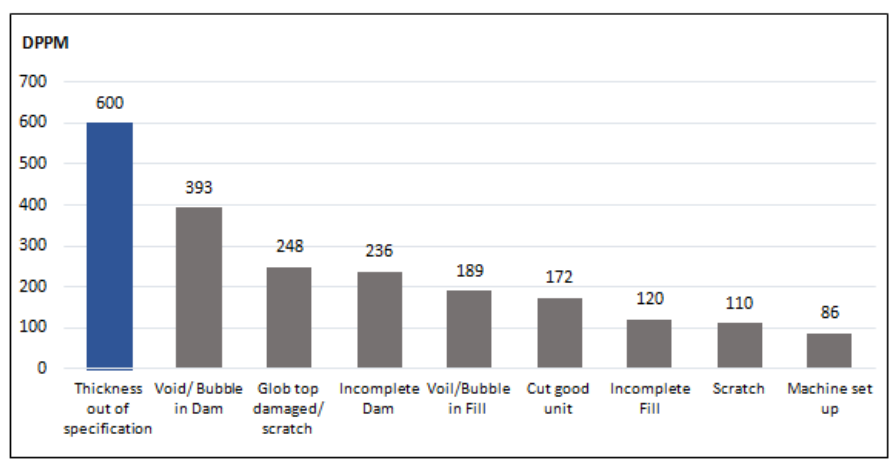

Figure 1. Defect Part Per Million defect in the process.

Therefore, the objective of this research is to identify the significant factors that cause the module warpage defect and to optimize relevant parameters of the encapsulation machines to reduce the problem. Six sigma approach was used as a tool in this study Montgomery \& Runger (2003). The key performance indicator used in this research was the defect part per million of the thickness out of specification.

\section{LITERATURE SURVEY}

\subsection{Six sigma}

Six sigma is considered as a well disciplined approach for process and product quality improvement through the effective use of projectdriven methodologies. The main aim of Six Sigma initiatives is to reduce costs or wastes as much as possible to improve quality of products to reach maximum satisfaction of customers and gain more profit for the producer. The Six Sigma methodology has evolved into a statistical approach to process, product and service quality improvement. The main phases of Six Sigma are called DMAIC, which is an acronym for the word of to define, measure, analyze, improve and control. In the define phase, the requirement and expectation of the customer and project boundary were defined. In the measure phase, the process to satisfy customer's needs is measured and data collection plan is also developed to collect and compare data to determine the issues. In the analyze phase, the causes of defects and sources of variation are analyzed and prioritized for future improvement. In the improve phase, the 
process is improved to eliminate variations, creative alternatives are developed and enhanced plan is also implemented. In control phase, the last phase, process variations are controlled to meet customer requirements, the improved process is monitored and controlled and the improvements of systems and structures also implemented (Wang, 2008).

\subsection{Gage study}

Gage repeatability and reproducibility (GR\&R) is the combination of the measurement systems between repeatability and reproducibility. Repeatability is variation in measurement obtained from one measuring instrument when used several times by an appraiser while measuring the identical characteristic on the same part. Repeatability is commonly referred to as equipment variation (EV). On the other hand, reproducibility is variation in the average of the measurement made by different appraisers using the same gage when measuring a characteristic on one part. Reproducibility commonly referred to as appraiser variation (AV). The guideline for acceptance is as follows: (1) accept if \%GR\&R less than $10 \%$, (2) accept with condition if $\% \mathrm{GR} \& \mathrm{R}$ is between $10 \%$ and $30 \%$, and (3) reject if \%GR\&R is over $30 \%$ (AIAG, 2010).

\subsection{Process capability}

The capability indices of $\mathrm{C}_{\mathrm{pk}}$ and $\mathrm{P}_{\mathrm{pk}}$ use the mean and standard deviation to estimate process capability to meet acceptable specification. The process capability can be measured under short term and long term aspects. Short term capability is to study a process performance for a certain operation run whereas, long term capability study is to study a variation data from a long period of time. Montgomery et al. (2001) provide guidelines on the values of $\mathrm{C}_{\mathrm{pk}}$ and $\mathrm{P}_{\mathrm{pk}}$ that the data must be normally distributed and the process must be in statistical control. The minimum values of $\mathrm{C}_{\mathrm{pk}}$ and $\mathrm{P}_{\mathrm{pk}}$ that are acceptable are equal to 1.33. If the process is used to produce safety products or products with critical characteristics, the value of $\mathrm{C}_{\mathrm{pk}}$ and $\mathrm{P}_{\mathrm{pk}}$ must be at least 1.66. For six sigma process, the values of $\mathrm{C}_{\mathrm{pk}}$ and $\mathrm{P}_{\mathrm{pk}}$ must be more than or equal to 2.0.

\subsection{Design of Experiment}

An experimental design is a disciplined plan for collecting and analyzing the data. A well-known type of the experimental design is the factorial design in which all possible combinations of the experiment of the levels of the factors are investigated. The level of the factors should be at least 2 levels. In this study, the $2^{\mathrm{k}}$ factorial design was used. Each factor has two levels, i.e. high and low which can be defined as (+) and (-), respectively. The $2^{\mathrm{k}}$ factorial design is applicable to the experiment with many factors. The analysis of the $2^{\mathrm{k}}$ factorial design allows us to identify significant main effects and the interactions between them. This finding can be used to setup the proper parameters for effective process control (Kaewon, 2013).

\subsection{Literature Review}

A number of research papers indicated an application of the Six Sigma approach was used for quality improvement and the defect reduction in semiconductor manufacturing companies. The reported results were satisfied and finally achieved the goal. Uy et al. (2010) studied the gap between Trim and Form process. The objective of the research was zero package cracks by using DMAIC which was a component of the Six Sigma methodology. They found that the die inserts with planarity influenced the package crack, and the die inserts with planarity should be less than 5 mils in order to eliminate package cracks was recommended.

Su et al. (2005) studied the approach to improve delamination quality. The delamination occurred due to a poor adhesion between wafer passivation and the assembly molding compound. Six Sigma was applied to improve the process. The research found various causes of delamination comprising a wafer passivation that had contact angle more than 100 degrees. In addition, high contaminations were found after molding compound process. Thus, the contact angle was suggested to be set between 60 and 70 degrees and the product should pass plasma cleaning after molding compound process. After implementation, the delamination had improved significantly, i.e. no delamination occurred and the pass rate was improved from $70 \%$ to $90 \%$.

\section{RESEARCH METHODOGY}

\subsection{Define phase}

Based on the company's historical data, the highest DPPM of the integrated circuit product was the thickness out of specification (i.e. 600 DPPM). Module warpage was identified to be the main problem that causes the thickness out of specification defect. Therefore, the study on the module warpage was conducted by comparing the warpage of all processes. Furthermore, we found that the encapsulation process had the highest module warpage as shown in Figure 2. The research then focused on the encapsulation process and how to reduce the module warpage. When the module warpage was reduced, the thickness out of specification defect could be reduced accordingly. 


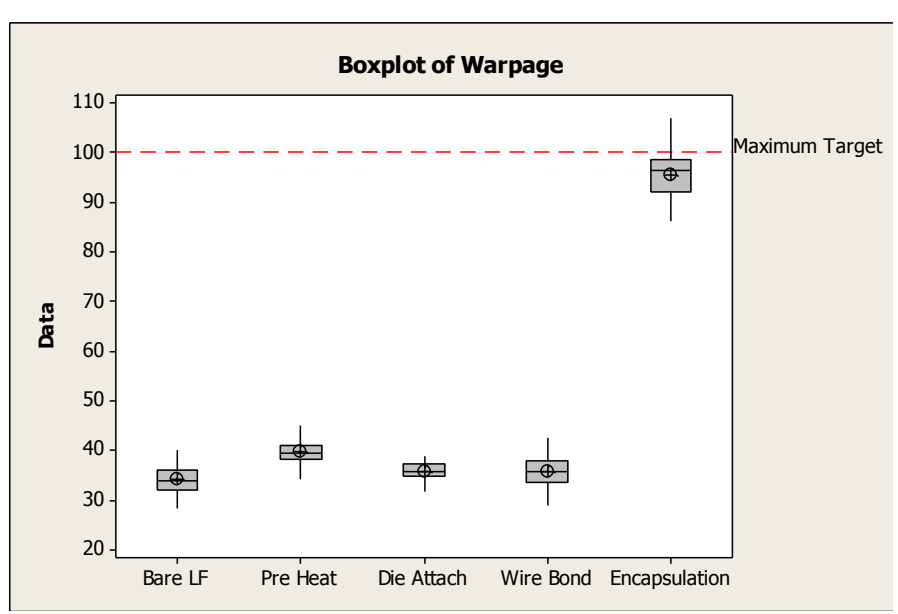

Figure 2. Warpage comparison of each process.

\subsection{Measure phase}

In this study, GR\&R was used for the repeatability and reproducibility analysis of non-destructive parts. The equipment's measurement system for module warpage measurement was analyzed by studying equipment and appraisers variations. Before performing GR\&R, the equipment had to pass the calibration. GR\&R started with the preparation of one equipment for module warpage measurement and two experienced appraisers. Ten samples were measured and two replicates were performed. The GR\&R result was less than $10 \%$ indicating that the measurement system is reliable (see Table 1 and Figure 3).

Table 1. GR\&R measurement result.

\begin{tabular}{|c|c|c|c|}
\hline \multicolumn{2}{|c|}{ Analysis items } & $\begin{array}{l}\text { Analysis } \\
\text { result }\end{array}$ & $\begin{array}{l}\text { Acceptance } \\
\text { criteria }\end{array}$ \\
\hline \multicolumn{2}{|c|}{ P-value of No. } & 0 & $\mathrm{P}$-value $<0.05$ \\
\hline \multicolumn{2}{|c|}{ P-value of Operator } & 0.684 & $\mathrm{P}$-value $>0.05$ \\
\hline \multicolumn{2}{|c|}{$\mathrm{P}$-value of $\mathrm{No}^{*}$ Operator } & 0.087 & P-value $>0.05$ \\
\hline \multicolumn{2}{|c|}{ Number of Distinct Categories } & 34 & $\geq 5$ \\
\hline \multirow{4}{*}{$\begin{array}{l}\text { \% Contributi } \\
\text { on of } \\
\text { VarComp }\end{array}$} & $\begin{array}{l}\text { Part-To-Part } \\
\text { Variation } \\
\end{array}$ & $99.83 \%$ & \multirow{4}{*}{$\begin{array}{l}\text { Measurement } \\
\text { system } \\
\text { variation } \\
\text { should be less } \\
\text { than process } \\
\text { variation } \\
\end{array}$} \\
\hline & Total Gage R\&R & $0.17 \%$ & \\
\hline & -Repeatability & $0.12 \%$ & \\
\hline & -Reproducibility & $0.05 \%$ & \\
\hline$\%$ Study Var & Total Gage R\&R & $4.11 \%$ & $\begin{array}{l}\% \text { Gage } R \& R< \\
30 \\
\end{array}$ \\
\hline \%Tolerance & $\begin{array}{l}\text { Part to Variation } \\
\text { ratio }\end{array}$ & $5.82 \%$ & $\begin{array}{l}\text { Part to Part } \\
\text { Variation ratio } \\
<30\end{array}$ \\
\hline
\end{tabular}

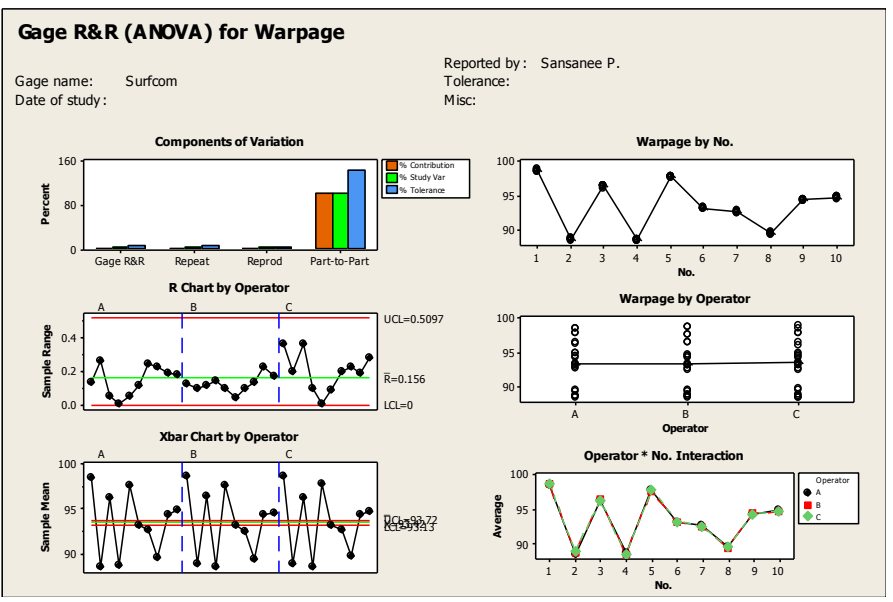

Figure 3. Gage study measurement system.

\subsection{Analyze phase}

The study team conducted brainstorming sessions to analyze various factors that impacted the module warpage. Cause and effect diagram was used to identify the potential factors that caused high module warpage. Cause and effect matrix was employed to identify the relationship between the response, i.e. module warpage and input factors. Score weights of each input factors were given by the study team. The score was summarized and Pareto chart analysis was performed to prioritize input factors. The input factors found to have the most influence high module warpage were pre-heat temperature, dam temperature, fill temperature and curing temperature. The $2^{4}$ full factorial design was used with three replicates at $95 \%$ confident level to determine the significant factors that affected the module warpage. The level of each input factors are identified as shown in Table 2.

Table 2. Input factors and level for design of experiment.

\begin{tabular}{|l|l|l|l|l|}
\hline Symbol & Input factor & $\begin{array}{l}\text { Low level } \\
(-1)\end{array}$ & $\begin{array}{l}\text { High } \\
\text { level (1) }\end{array}$ & Unit \\
\hline A & $\begin{array}{l}\text { Pre heat } \\
\text { temperature }\end{array}$ & 30 & 100 & $\begin{array}{l}\text { Degree } \\
\text { Celsius }\end{array}$ \\
\hline B & Dam temperature & 20 & 40 & $\begin{array}{l}\text { Degree } \\
\text { Celsius }\end{array}$ \\
\hline C & Fill temperature & 30 & 100 & $\begin{array}{l}\text { Degree } \\
\text { Celsius }\end{array}$ \\
\hline D & $\begin{array}{l}\text { Curing } \\
\text { temperature }\end{array}$ & 40 & 90 & $\begin{array}{l}\text { Degree } \\
\text { Celsius }\end{array}$ \\
\hline
\end{tabular}

The statistical analysis were done by Minitab software. The residual plot was normally distributed and no run pattern was noticed. The significant factors were dam temperature, fill temperature and curing temperature which had $\mathrm{p}$-value less than 0.05 at $95 \%$ confident level as shown in Figure 4. 


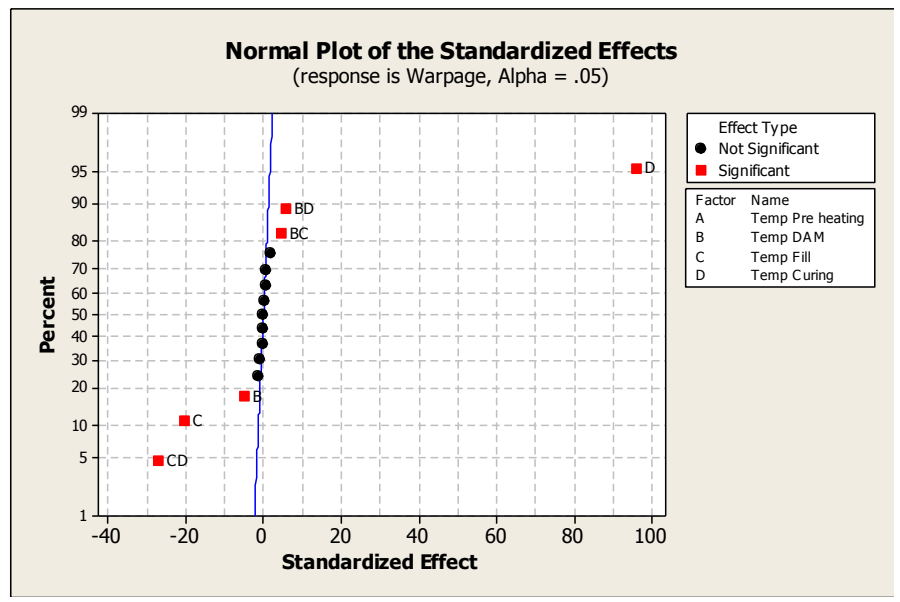

Figure 4. Significant factors for the module warpage.

\subsection{Improve phase}

The Box-Behnken design was used to optimize the levels of the significant factors. The design of experiment comprised three levels on each factor (Table 3). The target of module warpage was set at 45 microns. The result of the Box-Behnken design showed that the dam temperature, fill temperature and curing temperature were optimized at $30^{\circ} \mathrm{C}$, $65^{\circ} \mathrm{C}$ and $41^{\circ} \mathrm{C}$, respectively (Figure 5).

Table 3. Input factors and level for Box-Behnken design.

\begin{tabular}{|c|c|c|c|c|}
\hline Symbol & Input factor & $\begin{array}{c}\text { Low level } \\
(-1)\end{array}$ & $\begin{array}{c}\text { Middle level } \\
(0)\end{array}$ & $\begin{array}{c}\text { High level } \\
(1)\end{array}$ \\
\hline B & $\begin{array}{c}\text { DAM } \\
\text { temperature }\end{array}$ & 20 & 30 & 40 \\
\hline C & $\begin{array}{c}\text { Fill } \\
\text { temperature }\end{array}$ & 30 & 65 & 100 \\
\hline D & $\begin{array}{c}\text { Curing } \\
\text { temperature }\end{array}$ & 35 & 40 & 45 \\
\hline
\end{tabular}

\begin{tabular}{|c||c|c|c|c|}
\hline $\begin{array}{c}\text { Optimal } \\
\mathrm{D}\end{array} \mathrm{High}$ \\
$1.0000 \mathrm{Cur}$ \\
\hline \hline
\end{tabular}

Figure 5. Optimization significant factors.

\subsection{Control phase}

The optimized levels of each significant factor found from the Box-Behnken analysis were implemented in the process. The DPPM of the thickness out of specification was monitored for 1 month. It was found that DPPM was reduced from 600 to 184 . The cost saving from this project due to the reduction of the defects DPPM was estimated around 2.8 million baht/year. The control plan was established to monitor the warpage in the encapsulation process.

\section{CONCLUSION}

The DMAIC phases of the Six Sigma methodology is very effective in providing a framework for understanding the problem and conducting the analysis to identify the optimum levels to improve the process. In this research, the module warpage which is the main cause of the thickness out of specification defect is reduced after optimizing parameter settings of the dam temperature, fill temperature and the curing temperature of the encapsulation process. As a result, DPPM is decreased from 600 to 184 for this product.

\section{REFERENCES}

[1] Wang, H. 2008. A review of Six Sigma Approach: Methodology, Implementation and Future Research.

[2] AIAG. 2010. Measurement System Analysis. U.S.A: AIAG.

[3] Montgomery, D. \& Runger, G. 2003. Applied Statistics and Probability for Engineers. U.S.A: John Wiley \& Sons, Inc.

[4] Uy, A., Picardal, M., Enriquez, P. \& Alaraz, A. 2010. Package Crack Resolution through Low Stress Dambar Punch Design: A Six Sigma DMAIC Approach, $34^{\text {th }}$ International Electronic Manufacturing Technology Conference.

[5] Su, C., Chiang, T. \& Chiao, K. 2005. Optimizing the IC Delamination Quality via Six-Sigma Approach, IEEE Transactions on electronics packaging manufacturing: 241-248.

[6] Nagi, K. 2010. Applying Six Sigma for Quality Assessment in a eLearning Courseware Production Process, International Conference on Computer and Communication Engineering.

[7] Suriyasuphapong. S, 2013. Defective Reduction From Bending Defect on Hard Disk Drive Media. Bangkok: Chulalongkorn University.

[8] Kaewon, W. 2013. Reduction of Defectives from terminal color change of motorcycle. Bangkok: Chulalongkorn University.

[9] Montgomery, D., Peck, E. \& Vining, G. 2001. Introduction to Linear Regression Analysis. U.S.A: John Wiley \& Sons, Inc. 